\title{
A study of participation motives in sports, loneliness and depression levels of children with specific learning disabilities in terms of some variables ${ }^{1}$
}

\author{
Atike Y1lmaz ${ }^{2}$ \\ Menşure Aydın ${ }^{3}$ \\ Tolga Kaan Bahadir ${ }^{4}$ \\ Fikret Soyer ${ }^{5}$
}

\begin{abstract}
This study aims to examine the sport participation motivation, loneliness and depression levels of students with specific learning disabilities in terms of some variables. Screening model used in the study. The research group is constituted by 85 students who had been diagnosed with Specific Learning disabilities in Special Education and Rehabilitation Centers in Kocaeli province. Personal information form prepared by the researchers and developed by Gill, Gross and Huddleston (1983), and the Turkish validity and reliability study was made by Oyar, Aşçı, Çelebi and Mülazımoğlu (2001)."Sport Participation Motivation Scale", developed by Kovacs (1980) and the validity and reliability of the Turkish version was made by Öy (1991). "Depression Scale for Children" and developed Ashler ve Wheller (1985) and the validity and reliability of the Turkish version was made by Kaya (2005) "Loneliness Scale for Children" were used as the data collection tools. The sports participation motives, depression and loneliness levels of the participants have been evaluated in terms of age, gender, natural / adoptive parents, family's economic status, father's occupational status, number of people in the family, number of siblings, family attitude and the state of doing sport. In the evaluation of the research data, descriptive statistics, t-test, ANOVA test and correlation analysis were used. In the findings, sports participation motives of participants were significantly differ according to the gender, family attitudes and the status of doing sports. Also according to the age, in loneliness level, and according to the number of siblings in the levels of loneliness and depression, significant differences were found. As a result of the correlation, a positive relationship between depression and loneliness status of the participants was found. Thus, in children at the 9-14 age range with specific learning disability it was concluded that the family attitude, number of siblings and to do sports have an impact in a positive way on the loneliness, depression and sports participation.
\end{abstract}

Keywords: Specific learning disabilities, depression, loneliness, sport participation motivation

\footnotetext{
1 Abstract of this study was presented as an oral presentation at Teacher Education In Special Education, Vocational Training And Sports" (Elmis 2016), 12-15 May 2016, Konya/Turkey

${ }^{2}$ Assist. Prof., Muş Alparslan University, School of Physical Education and Sports, Department of Exercises and Sports Teaching For The Disabled, atiketan@gmail.com Orcid ID: 0000-0003-4489-9671

3 Assoc. Prof., Halic University, School Of Physical Education And Sports, Department Of Recreation, mensureaydin@halic.edu.tr Orcid ID: 0000-0002-4250-4990

${ }^{4}$ Assoc. Prof., Kocaeli University, Faculty Of Sports Sciences, Department Of Physical Education And Sports Education, tolga.bahadir@,kocaeli.edu.tr Orcid ID: 0000-0002-3959-0613

5 Prof. Dr., Balikesir University, School Of Physical Education And Sports, Department Of Sports/Department Of Sports Management, fikretsoyer@gmail.com Orcid ID: 0000-0002-8528-3622
} 
Yilmaz, A., Aydın, M., Bahadır, T. K., \& Soyer, F. (2019). A study of participation motives in sports, loneliness and depression levels of children with specific learning disabilities in terms of some variables. Journal of Human Sciences, 16(4), 978-987. doi:10.14687/jhs.v16i4.5600

\section{Introduction}

The Specific Learning Disabilities (SLD) manifests themselves by the existence of significant impairments in a specific academic field. The distribution of the cognitive ability of the children who are diagnosed with it is like roller coaster ride. This different distribution includes different and wide competence areas such as reading, writing, listening and speaking (Korkmaz, 2000; Talbot, Astbury ve Mason, 2010). According to DSM-V (APA, 2013) the Developmental Learning Disabilities are examined within three groups including; special learning disabilities, communication disorders and motor skill disorders. The special learning disabilities include the difficulties in the field of reading, writing and mathematics (Peleg, 2009). Communication difficulties include the phonological disorders, expressive language disorders and the receptive and expressive mixed language disorder. The Motor skill disorders emphasize the disorders within the motor coordination. These three elements are not independent from each other. Mainly they have intertwined structures. Especially the special learning disabilities and communication disorders are usually observed simultaneously (Öktem, 1999). It was stated that this kind of disorders are frequently observed along with mental problems and behavioural disorders (Sharma, 2004; Cortiella ve Horowitz, 2014). This study intended to investigate the feelings of depression and loneliness in children who were diagnosed with specific learning disabilities.

Nowadays, the existence of depression is also detected in children (Öy, 1990), it occurs with symptoms similar to the symptoms of the adults therefore the adult depression criteria is also valid for the children if some features are considered according to the age (Şener,1994). Kavale (2002) emphasized that these children often demonstrated the signs of depression and could not control their worries and anxiety emotions due to their failure at school. The anxiety and depression signs are more common especially in children with reading difficulties. Besides, the children who are experiencing these problems are considered to experience the feeling of loneliness too.

It can be explained as an undesirable and unpleasant experienced followed by the feelings of loneliness, anxiety, anger, sadness and the feeling of being different from the others (Ditomasso \& Spinner 1997).

One of the ways that can help the child diagnosed with special learning disabilities to cope all these mental problems is exercising physical activities.

Sports which has become an important part of the social life does not improve only the quality of life but has also therapeutic effect on depression (Dowall et al., 1988), exercise was reported to increase the capacity of coping with stress (Pollatschek \& O'Hagan, 1989) and to reduce depression and anxiety (Abele \& Brehm, 1983). Additionally Ekeland et al. (2005) stated that the physical activity had positive impact on the self-esteem and behavioural problems of the children and adolescence. Based on all these, in this research it was intended to investigate the motivation of participation in sports and the levels of loneliness and depression in children with Specific Learning Disabilities in terms of certain variables.

\section{Methods}

\section{Research Model}

In this study, the general screening model which is one of the descriptive research methods was used. According to Karasar (2005) it was defined as a research approach which intended to define an existing situation as it is.

\section{Participants}

The sample group consisted of 85 students aged between 9 and 14 who were diagnosed with Specific Learning Difficulties in the province of Kocaeli. The questionnaires were applied to the participants on days when they attended special education. 
Yilmaz, A., Aydın, M., Bahadır, T. K., \& Soyer, F. (2019). A study of participation motives in sports, loneliness and depression levels of children with specific learning disabilities in terms of some variables. Journal of Human Sciences, 16(4), 978-987. doi:10.14687/jhs.v16i4.5600

\section{Data Collection Tools}

\section{Sport Participation Motivation}

The Sport Participation Motivation Scale which was developed by Gill, Gross and Huddleston in 1985 consists of 30 items and 8 sub-dimensions (Skills Improvement, Team Membership/ Spirit, Fun, Friendship, Success/ Status, Physical Fitness, Competition and Motion) including the reasons for participating in sports. The children's reasons for participating in sports were evaluated with a triplex scale in the following way; "Very Important 1", "Less Important 2" and "Not important at all 3". Items included within the "Sport Participation Motivation Scale" 1 were evaluated between 1 (Very Important) to 3 (Not Important at All) and the obtained lower values demonstrated that that item was more important. The scale was translated into Turkish by Çelebi (1993) while the reliability and validity for the Turkish students were carried out by Oyar, Aşçi, Çelebi and Mülazımoğlu (2001). In this study the "Sports Participation Motivation Scale" Cronbach's alpha reliability coefficient for the boys was found to be 0,87 .

\section{Children's Depression Scale}

The Children's Depression Scale (CDS) was developed by Kovacs in 1980 on the basis of Beck's Depression Inventory by adding depression specific questions related to school and peer relations. The validity and reliability study for Turkey was carried out by Öy (1991). The test-retest reliability of the scale was found to be .72 while the internal consistency coefficient was found to be .86. The Children's Depression Scale is a 27 -item scale. Its language was simplified so that the children between 6 and 17 could easily understand. The scale is filled after being read to the child or being read by the child itself. There are three different options for each item. Each item should be scored from 0 to 2 according to the severity of the symptoms. The child is asked to assess his own state in the last two weeks and choose the most appropriate option out of the three options. The maximum score is 54 and the cut-off point is 19. The higher the obtained score is (compared to 19) the severe the depression can be considered (Öy, 1991).

\section{Children's Loneliness Scale}

This scale which was developed by Ashler and Wheller (1985) and was adapted to Turkish by Kaya (2005) whose validity and reliability test was carried out is a five Likert -type scale and is marked according to the following five degrees "always true", "mostly true", "sometimes true", "not true" and "not true at all". The scale consists of 23 items. However the result of the performed reliability analysis showed the integrity of 15 items with a reliability coefficient of $r=.87$. Therefore the No. 1, 4, 6, 10, 12, 14, 18, and 22 items were used as fillers and were not taken into account during the calculation of the scores obtained from the scale. Additionally the No 3,7,9,15,21 items were defined as reverse scored items. The lowest score which can be obtained from the scale is 15 while the highest score is 75 . The experienced sense of loneliness is directly proportional to the score obtained from the scale. The higher score is obtained the more loneliness is experienced (Kaya, 2005).

\section{Data Analysis}

The statistical analysis of the data obtained from the study was conducted in the SPSS 20.0 program. Descriptive statistics and normality tests were applied in the analysis of the data, and since the data did demonstrate a normal distribution, Annova test, independent $\mathrm{t}$-test and $\mathrm{R}$ correlation test were employed, which are among the parametric tests. As a result of the analysis, meaningful results are given due to the large number of tables. 
Yilmaz, A., Aydın, M., Bahadır, T. K., \& Soyer, F. (2019). A study of participation motives in sports, loneliness and depression levels of children with specific learning disabilities in terms of some variables. Journal of Human Sciences, 16(4), 978-987. doi:10.14687/jhs.v16i4.5600

\section{Results}

Table 1: The Demographic Profile of the Participants Descriptive Statistics

\begin{tabular}{|c|c|c|c|c|c|c|c|}
\hline & & f & $\%$ & & & $\mathbf{f}$ & $\%$ \\
\hline \multirow{3}{*}{ Gender } & Girl & 39 & $45,9 \%$ & Family's & Low & 7 & $8,2 \%$ \\
\hline & Boy & 46 & $54,1 \%$ & Economic & Medium & 65 & $76,5 \%$ \\
\hline & $9-11$ & 33 & $38,8 \%$ & Condition & High & 13 & $15,3 \%$ \\
\hline \multirow[t]{2}{*}{ Age } & Disinterested & 8 & $9,4 \%$ & \multirow{4}{*}{$\begin{array}{l}\text { Number } \\
\text { of } \\
\text { siblings }\end{array}$} & 1 sibling & 14 & $16,5 \%$ \\
\hline & No & 60 & $70,6 \%$ & & 2 sibling & 40 & $47,1 \%$ \\
\hline \multirow{2}{*}{$\begin{array}{l}\text { Sport } \\
\text { Participation }\end{array}$} & Yes & 25 & $29,4 \%$ & & 3 sibling & 25 & $29,4 \%$ \\
\hline & Total & 85 & $100,0 \%$ & & $\begin{array}{l}4 \text { sibling } \\
5 \text { sibling }\end{array}$ & $\begin{array}{l}5 \\
1\end{array}$ & $\begin{array}{l}5,9 \% \\
1,2 \%\end{array}$ \\
\hline
\end{tabular}

According to Table 1, $45.9 \%$ (39) of the participants were girls while $54.1 \%$ of them were boys (46). According to the age distribution $38.8 \%$ of them (33) were between 9 and $11,61.3 \%$ were at the age between 12 and 14 (52). When considering the attitude of the family $7.1 \%(6)$ were authoritarian, $83.5 \%$ (71) were democratic and $9.4 \%(8)$ were identified as disinterested. When looking in terms of making sports 70,6\% (60) do not attend any sport activities while $29.4 \%(25)$ were identified as attending sport activities. According to the economic situation of the family 8.2 $\%$ (7) stated to be in the low income group, 76,5\% (65) were stated to be in the middle groups while $15.3 \%$ (13) stated to be in the high income group. In terms of the siblings, $16.5 \%$ of the participants (14) were single child, $47.1 \%$ of them (40) had one sister / brother, 29,4\% (25) had 2 sisters /brothers, $5.9 \%(5)$ had 3 sisters/brothers while $1.2 \%$ (1 child) had 4 sisters/brothers. There were a total of 85 participants.

Table 2: The independent $\mathrm{T}$ test statistics of Loneliness and Sports Participation Motivation According to the Age

\begin{tabular}{lccccc}
\hline Loneliness & & $\mathbf{n}$ & Mean & SD & $\mathbf{p}$ \\
\hline \multirow{2}{*}{ Age } & $9-11$ & 33 & 75.58 & 7.27 & \multirow{2}{*}{0.01} \\
\hline $\begin{array}{l}\text { Sports Participation } \\
\text { Motivation }\end{array}$ & $12-14$ & 52 & 68.5 & 5.54 & p \\
\hline \multirow{2}{*}{ Competition } & Girls & 39 & Mean & SD & \multirow{2}{*}{0.01} \\
\hline
\end{tabular}

Significance level $\mathrm{P} \leq 0,05$

In Table 3 significant difference was observed in the independent t test statistics of the loneliness and sports participation motivation according to the age. According to the age group 911 (mean 75.58 and S.S. 7.27) and age group of 12-14 (mean 68.5 and S.S. 5.54) $\mathrm{P} \leq 0,05$ therefore there was a significant difference. In the competition sub-dimension the sports participation motivation of the female participants (mean 1,65 and ss.0,51) was higher than the male participants (mean 1.36, ss0.44). There was statistically no significant difference Depression levels according to the age and gender. There was statistically no significant difference Loneliness levels according to the gender and sports participation motivation according to the age. 
Yilmaz, A., Aydın, M., Bahadır, T. K., \& Soyer, F. (2019). A study of participation motives in sports, loneliness and depression levels of children with specific learning disabilities in terms of some variables. Journal of Human Sciences, 16(4), 978-987. doi:10.14687/ihs.v16i4.5600

Table 3: The Anova test statistic results of the Sports Participation Motivation according to the Economic Status of the Family and the Family Attitudes

\begin{tabular}{|c|c|c|c|c|c|}
\hline & & $\mathbf{N}$ & Mean & SD & $\mathrm{p}$ \\
\hline & Low & 7 & 1.5 & 0.5 & \multirow{5}{*}{0.01} \\
\hline Skill & Medium & 65 & 1.17 & 0.31 & \\
\hline \multirow[t]{3}{*}{ Development } & High & 13 & 1.44 & 0.61 & \\
\hline & Total & 85 & 1.24 & 0.4 & \\
\hline & Low & 7 & 1.71 & 0.87 & \\
\hline \multirow{3}{*}{ Success } & Medium & 65 & 1.21 & 0.34 & \multirow{2}{*}{0.01} \\
\hline & High & 13 & 1.19 & 0.31 & \\
\hline & Total & 85 & 1.25 & 0.42 & \multirow{6}{*}{0.01} \\
\hline \multirow{5}{*}{ Fun } & Low & 7 & 1.69 & 0.79 & \\
\hline & Medium & 65 & 1.23 & 0.32 & \\
\hline & High & 13 & 1.2 & 0.37 & \\
\hline & Total & 85 & 1.27 & 0.4 & \\
\hline & Low & 7 & 1.86 & 0.84 & \\
\hline Physical & Medium & 65 & 1.27 & 0.41 & \multirow[t]{3}{*}{0.01} \\
\hline \multirow[t]{2}{*}{ Fitness } & High & 13 & 1.35 & 0.58 & \\
\hline & Total & 85 & 1.33 & 0.5 & \\
\hline \multirow{5}{*}{ Motion } & Low & 7 & 1.64 & 0.63 & \multirow{5}{*}{0.02} \\
\hline & Medium & 65 & 1.19 & 0.36 & \\
\hline & High & 13 & 1.42 & 0.64 & \\
\hline & Total & 85 & 1.26 & 0.45 & \\
\hline & Authoritarian & 6 & 1.25 & 0.42 & \\
\hline \multirow{3}{*}{$\begin{array}{l}\text { Skill } \\
\text { Development }\end{array}$} & Democratic & 71 & 1.19 & 0.33 & \multirow{3}{*}{0.01} \\
\hline & Disinterested & 8 & 1.63 & 0.69 & \\
\hline & Total & 85 & 1.24 & 0.4 & \\
\hline \multirow{4}{*}{ Motion } & Authoritarian & 6 & 1.25 & 0.42 & \multirow{4}{*}{0.02} \\
\hline & Democratic & 71 & 1.22 & 0.4 & \\
\hline & Disinterested & 8 & 1.69 & 0.7 & \\
\hline & Total & 85 & 1.26 & 0.45 & \\
\hline \multirow{4}{*}{ Friendship } & Authoritarian & 6 & 1.61 & 0.65 & \multirow{4}{*}{0.02} \\
\hline & Democratic & 71 & 1.22 & 0.33 & \\
\hline & Disinterested & 8 & 1.75 & 0.85 & \\
\hline & Total & 85 & 1.29 & 0.46 & \\
\hline
\end{tabular}

Significant at $\mathrm{p} \leq 0.05$

In Table 4, according to the Anova test statistics significant result $\mathrm{p}<0,05$ occurred in the sub-dimension of the Sports Participation Motivation according to the economic status of the families. In the family attitudes significant relation $p<0,05$ occurred in the Anova test statistics in the skill development, motion and friendship sub dimensions of the Sports Participation Motivation Scale according to the family attitudes, significant relation was not observed in the following sub-dimensions; team membership, success, fun, physical fitness, and competence. There was statistically no significant difference Depression and Loneliness levels according to the economic status of the family and the family attitudes. 
Yilmaz, A., Aydın, M., Bahadır, T. K., \& Soyer, F. (2019). A study of participation motives in sports, loneliness and depression levels of children with specific learning disabilities in terms of some variables. Journal of Human Sciences, 16(4), 978-987. doi:10.14687/jhs.v16i4.5600

Table 4: The Anova test statistic results of the Depression and Loneliness according to the Number of Siblings

\begin{tabular}{llcccc}
\hline & N & Mean & SD & p \\
\hline \multirow{4}{*}{ Depression } & 1sis/bro & 14 & 22.64 & 2.71 & \\
& 2sis/bro & 40 & 24.23 & 3.63 & 0.02 \\
& 3sis/bro & 25 & 25.36 & 2.61 & \\
& 4sis/bro & 6 & 27.17 & 3.49 & \\
& Total & 85 & 24.51 & 3.35 & \\
& 1sis/bro & 14 & 70.64 & 5.51 & \\
& 2sis/bro & 40 & 69.03 & 6.44 & \\
& 3sis/bro & 25 & 73.16 & 6.8 & \\
& 4sis/bro & 6 & 79.5 & 9.38 & \\
& Total & 85 & 71.25 & 7.13 & \\
\hline
\end{tabular}

Significant at $\mathrm{P} \leq 0,05$ level

In Table 5, significant relationship occurred $\mathrm{P} \leq 0,05$ according to the Anova test statistics of the Depression and Loneliness levels according to the numbers of siblings. There was statistically no significant difference Sports Participation Motivation according to the siblings.

Table 5: Depression and Loneliness R Correlation Test

Depression

Loneliness

\begin{tabular}{llcc}
\hline Depression & $\mathrm{r}$ & 1 & \\
& $\mathrm{p}$ & $.371^{* *}$ & 1 \\
Loneliness & $\mathrm{r}$ & 0 & \\
\hline
\end{tabular}

In Table 6 the depression and loneliness correlation test of the children aged 9-14 diagnosed with specific learning difficulties occurred positively significant at $\mathrm{p} \leq 0,05$ level.

\section{Discussion and Conclusions}

The discussion of the study done as a result of the findings is carried out with similar studies due to the fact that the literature was limited on this issue, in this sense it is believed that this study will be helpful for the future studies. In this study the sport participation motivation, loneliness and depression levels of the children diagnosed with specific learning difficulties were analysed in terms of some variables. When examining the loneliness and sports participation motivation from the obtained findings according to the age between 9 and 11 (mean 75,58 and ss. 7,24) and between 12 and 14 (mean 68,5 and ss5,54), it was observed that the loneliness level of the children with specific learning difficulties aged between 9 and 11 was higher compared to the children with the same difficulties aged between 12 and 14. It is suggested that the fact that younger age groups had less socialization experiments affected this issue. In addition, children with disabilities especially those with mental disabilities and learning difficulties are more prone to loneliness than their peers showing normal development (Margalit and Levin Alyagon, 1994). The disabled students are experiencing higher rates of loneliness for two main reasons. Many of the disabled students have difficulties in processing and becoming aware of social clues and in developing social relations therefore they are less accepted by their peer groups (Haager and Vaughn, 1995). Most of the students have difficulties 
Yilmaz, A., Aydın, M., Bahadır, T. K., \& Soyer, F. (2019). A study of participation motives in sports, loneliness and depression levels of children with specific learning disabilities in terms of some variables. Journal of Human Sciences, 16(4), 978-987. doi:10.14687/jhs.v16i4.5600

in expressing themselves appropriately in social situations and exhibit behaviour that result in rejection by their peers. Although a part of the children having specific learning difficulties do not have any kind of problem visually, auditory, mentally, emotionally or socially they may have difficulties in one or all of the following fields; reading, writing, speaking or arithmetic (Wong, 1998). These experienced difficulties on one hand prevent the children from being successful in school while on the other hand because of the inability to understand the main reason of this failure both the child and the parents will be responsible for this failure (Rea, Mclaughlin and Walter-Thomas, 2002).Negative effects are concerned in the personal development of the children who have difficulties in formal education, feel themselves different from their peers and who have broken relations with their parents and teachers. Secondary mental health problems such as depression, anxiety disorders, shaken self-confidence, loss of self-esteem and loneliness increase the experienced difficulties (Erdem, Kurdoğlu and Uslu, 2002). This study also seems to support the occurrence of high level loneliness in younger age group. It is clear that loneliness and other problems are experienced more severe at an early age because of the delay in the diagnosis and during the process when the family, teacher and the child accepts the situation after the diagnosis.

According to the other finding of the research, in the competition sub-dimension of the sports participation motivation scale higher results were obtained in favour of the female participants. Based on this, it can be stated that the sports participation motives of the female participants in the competition sub-dimension were more advanced and their competition motivations were higher compared to men. In line with our research, in a study made by Er et al. (2003) on the issue of "Analysis of the Sports Achievement Motivation in terms of the Genders" the power showing motivation was reported to be higher in the female participants. But in the study of Altuntaş and Bayar Koruç (2014) on the issue of the determination of the young athletes' sport participation motivation according to the type of sports and gender; it was stated that no difference was found in the young athletes' participation motivations according to the gender. Additionally, the desires of the young athletes participating in team sports to meet other people, to make new friends and to be a part of a team were higher compared to the others. These findings are not in line with our study. Based on this, it was concluded that the gender differences were not always effective.

Therefore, it should be considered that each child participated in sports by being affected through different motivations. Another important issue is to conclude that the motivations varied according to the age, gender, type of sports and the level of experience. According to other findings significant differences were obtained at the $\mathrm{p}<0,05$ level in the sub-dimensions of skill development, success, fun, physical fitness and motion on the sports participating motivation scale according to the economic situation of the family. The owned socio-economic level affects the sport participation dimensions. People from different socio-economic classes participate at sports in our society and it was detected that people with low and middle income participated (Hacicaferoğlu, 2014). In another finding of the study significant relation was detected at the depression and loneliness levels according to the number of the siblings. In a study made by Avci et al. (1996) the depression scores was analysed in terms of the number of siblings and the depression scores of the single children and of those with more than 2 siblings were found to be low. The studies which were conducted by Yüksek (1999) were in line with our work. It can be concluded that with the increase in the number of siblings the participants' depression and loneliness level is increasing. Besides, in the study of Özdel et al (2002) which was conducted on the issue of "Investigating the relationship between the depressive symptoms and the socio-demographic features of the university students" it was stated that with the increase in the number of siblings the ratio of demonstrating depressive symptoms is reduced. From this it can be concluded that the number of siblings affects the levels of depression and loneliness, however this effect decreases with the age. According to other obtained findings; significant relation was observed in the skill development, motion and friendship sub-dimensions of the Sports Participation Motivation Scale while significant relation was not obtained from the team membership, success, fun, physical fitness and competition sub-dimensions. From this it was obvious that the 
Yilmaz, A., Aydın, M., Bahadır, T. K., \& Soyer, F. (2019). A study of participation motives in sports, loneliness and depression levels of children with specific learning disabilities in terms of some variables. Journal of Human Sciences, 16(4), 978-987. doi:10.14687/jhs.v16i4.5600

families thought to meet the motion needs, to develop their skills and to meet the children's need to socialize beside their friendship due to these the three sub-dimension occurred to be significant. In the study of Pehlivan (2009) entiteled as " Family expectations towards the children participating in sports, the behaviour changes observed in the children and the obstacles in front of the participation in Sport" the five most important expectations for sending the children to sport school were listed in the following way; first row " acquiring the habit for doing sports regularly", second row "gaining team spirit, sharing, cooperation and solidarity", third row "protecting and improving health", fourth row "gaining achievement and status" and in the fifth row "acquiring and improving skills". "Learning to compete", "fun" and "increasing school success" is in the last row. These are partially supporting our study. However, the fact that both the family and the child have the same idea about the participation is sports is important in predicting the results (Kanters et al., 2007). Gren and Chalip (1997) reported that there was a relationship between children's participation in sports and the satisfaction of the child and family. In the same study it was also stated that the satisfaction of the children and family played an important role in continuing the sport, the value system of the families about the importance of the sport for their children, the expectation of the children towards the success in sport and the past participations of the families in sports were shaped. According to other findings; the depression and loneliness correlation test of the children aged between 9 and 14 who were diagnosed with specific learning difficulties was found to be positively significant. From this it can be concluded that with the increase in the depression level the loneliness level also increases. As a result of a study conducted on 333 university students in relation with loneliness and depression it was reported that correlation was found between depression and loneliness and even if they were not the reasons for each other they shared the same or similar ground in terms of the beginning (Weeks et al., 1980). Horowitz et al. (1982) suggested that depression was a wide concept including many of the loneliness' effects. It was also supported by various studies that the children having especially reading difficulties the symptoms of anxiety, loneliness, worry and depression were observed more often (Sharma, 2004). The positive direction of our findings lends to support these studies.

When looking at the obtained results the followings could be stated; the competition motivation of the female participants were higher compared to the male participants, the skill development, team membership, success, fun, physical fitness, competition, motion and friendship in the sub-dimensions of the sports participation motivation were found to be significant in favour of those making sport and that sport had positive impact on children who were diagnosed with specific learning difficulties. The repetition of this study including different disability groups and the re-assessment of the results could contribute to our study.

\section{References}

Abele, A., Brehm, W. (983). Moods and effeçts of exercise versus sports games: findings and implications for well-being and health, Intern Review of Health Psychology, 2:53: 80

Altıntaş, A., Bayar-Koruç, P. (2014). Determınıng partıcipation motıvatıon of young athletes with regard to gender and sport type, International Journal of Science Culture and Sport July Special Issue 1: $61-67$

American Psychiatric Assosication. (2013). Diagnostic and statistical manual of mental disorders (DSM-5) (5th ed.). Arlington, VA: American Psyhiatric Publishing.

Asher, S.R. ve Wheeler, V.A. (1985). Children's loneliness: A comparison of rejected and neglected peer status. Journal of Consulting and Clinical Psychology, 53, 500-505.

Cortiella, C., \& Horowitz, S. H. (2014). The state of learning disabilities: Facts, trends and emerging issues (3rd ed.). New York: National Center for Learning Disabilities.

Çelebi, A. M. (1993). The Middle East Technucal Unversity, Types of Physical Activity Club Leader Found, Unpublished master's thesis, Ankara.

Ditommaso, E., Spinner, B. (1997). Social and emotional loneliness: a reexamination of weiss' typology of loneliness, Personality and Individual Differences. 22: 417-427. 
Yilmaz, A., Aydın, M., Bahadır, T. K., \& Soyer, F. (2019). A study of participation motives in sports, loneliness and depression levels of children with specific learning disabilities in terms of some variables. Journal of Human Sciences, 16(4), 978-987. doi:10.14687/jhs.v16i4.5600

Dowall, J.R., Bolter, C.P., Flett, R.A. and Kammann, R. (1998). 'Psychological well-being and its relationship to fitness and avtivity levels'J Hum. Movement Stud. 439-45

Ekeland, E., Heian, F. and Hagen, K.B. (2005). Can exercise improve self esteem in children and young people? a systematic review of randomised controlled trials. British Journal Of Sports Medicine, 39:792-798.

Er, N., Çobanoğlu, G., Er, G., Zekioğlu, A. and Yazıcılar, İ. (2003). An analysis of gender and sports achievement motivation ", Physical Education and Sports Poster presented at the Congress of Social Sciences, Ankara, 10-11 October.

Erden, G., Kurdoğlu, F. ve Uslu, R. 22 . Development of grade level norms for reading speed and writing errors of Turkish elementary school children. Turkish Journal of Psychiatry, 13 (1): $15-13$

Gill, D.L, Gross, J.B., \& Huddleston, S. (1985). Participation motivation in youth sports. Intematiortal Journal of Sports Psychology, 14, 1-14

Gren, C.B., Chalip, L. (1997). Enduring involvement in youth soccer: the socialization of parent and child". Journal of Leisure Research, 29(1):61-77

Haager, D., Vaughn, S. (1995). 'Parent, teacher, and self-reports of the social competence of students with learning disabilities, Journal of Learning Disabilities, 28: 205-215.

Hacicaferoğlu, S. (2014). 'The examination of the socio-economic profiles of the players who participate in the folk dances discipline, inonu university', Journal Of Physical Education And Sport Sciences, 1(1):14-24

Horowitz, L.M., Frenst, R.D.S. and Anderson, C.A. (1982). The Prototype of a Lonely Person. A Sourcebook of Current Theory. Research and Therapy, Peplau LA (Ed), New York, VViley Press, 183.

Kanters, M.A., Bocarro, J. and Casper, J. (2007). Supported or pressured? An examination of agreement among parent's and children on parent's role in youth sports, Journal of Sport Behavior. 31(1):64-80.

Karasar, N. (2009). Research Methods, Ankara; Nobel Publications.

Kavale, K.A. (2002). Discrepancy models in the identification of learning disability. In R. Bradley, L. Danielson, \& D. P. Hallahan (Eds.), Identification of learning disabilities: Research to practice (pp. 369-426). Mahwah, NJ: Erlbaum.

Kaya, A. (2005). The Validity and Reliability Study ofthe Turkish Version oftheChildren's Loneliness Scale, Eurasian Journal of Educational Research, 19:1-19.

Korkmaz, B. (2000). Learning Disorders Pediatric Behavioral Neurology, İstanbul University Publications, İstanbul, 189-216.

Kovacks, M. (1985). The Children's Depression İnventory. Psychopharmacology Bulletin,

21, 995-998.

Margalit, M., Levin-Alyagon, M. (1994). 'Learning disability subtyping, loneliness, and classroom adjustment., Learning Disability Quarterly, 17:297-310.

Oyar, Z.B., Aşçı, F.H., Çelebi, M. and Mülazımoğlu, Ö. (2001). Validitv and reliability of "participation motivation questionnaire, Hacettepe Journal of Sport Sciences; 12(2):21-32.

Öktem, Ö. (1999). A developmental learning disabilities (developmental dyslexia), I'm not patient. A Ekşi (Ed), İstanbul, Nobel Publucation, 300-309.

Öy, B. (1990). Childhood Depression; History, Classification and Diagnostic Criteria' Turkish Journal of Psychiatry, 1(2):21-24

Öy, B. (1991). 'Depression scale for children: validity and reliability study', Turkish Journal of Psychiatry, 2(2): 132-136.

Özdel, L., Bostanc1, M., Özdel, O. \& Oğuzhanoğlu, N.K. (2002). The relationship between depressive symptoms and sociodemographic characteristics among university students, Anatolian Journal of Psychiatry, 3:155-161. 
Yilmaz, A., Aydın, M., Bahadır, T. K., \& Soyer, F. (2019). A study of participation motives in sports, loneliness and depression levels of children with specific learning disabilities in terms of some variables. Journal of Human Sciences, 16(4), 978-987. doi:10.14687/ihs.v16i4.5600

Pehlivan, Z. (2009). The expectatıons of the families from their children who are participating sports, behavioral changes that are observed in children and obstacles to participation to sports. Ankara University Faculty of Sport Sciences Spormetre, 7(2): 69-76.

Peleg, O. (2009). Test anxiety, academic achievement and self-esteem among arab adolescents with and without learning disabilities. Learning Disability Quarterly, 32:11-20

Pollatschek, J. L., O'hagan, F. J. (1989). An investigation of the psycho-physical influences of a quality daily physical education programme, Health Education Research:Theory and Practice, 4:341-350

Rea, P. J., Mclaughlin, V. L. \& Walter-Thomas, C. (2002). Outcomes for students with learning disabilities in inclusive and pullout programs, Exceptional Children, 68(2):203-223.

Sharma, G. (2004). A Comparative study of the personality characteristics of primary school students with learning disabilities and their non learning disabled peers, Learning Disability Quarterly, 27(3):127-140.

Şener, S. (1994). Depression in children and adolescents. Depression Monograph Series, 7:313-326

Talbot, P., Astbury, G., \& Mason, T. (2010). Key concepts in learning disabilities. London: SAGE Publications.

Weeks, D. G., Michels, J. L. \& Peplau, L. A. (1980). Relation betvveen loneliness and depression: a structured equation analysis, J Pers Soc Psychol, 39:1238-1244.

Wong, B. Y. L. (1998). Learning about learning disabilities. San Diego:Academic Press.

Yüksek, H. (1999). Through Behavioral Assessment Scale for the Assessment of children with ADHD esspatoloji, Unpublished master's thesis. Istanbul University Institute of Social Sciences, İstanbul. 